\title{
The Effects of a Warm or Chilly Climate towards Socioeconomic Diversity on Academic Motivation and Self-Concept
}

\author{
Alexander S. Browman and Mesmin Destin \\ Northwestern University \\ In press at Personality and Social Psychology Bulletin \\ doi: $10.1177 / 0146167215619379$ \\ Note: This document represented the accepted but pre-copyediting version of this \\ article. Please defer to the published version — available at the DOI link above- \\ for the official final versions of all text, statistics, figures, and tables.
}




\begin{abstract}
Persistent academic achievement gaps exist between university students from high- and lowsocioeconomic status (SES) backgrounds. The current research proposes that the extent to which a university is perceived as actively supporting versus passively neglecting students from diverse socioeconomic backgrounds can influence low-SES students' academic motivation and selfconcepts. In Experiments 1 and 2, low-SES students exposed to cues suggestive of an institution's warmth towards socioeconomic diversity demonstrated greater academic efficacy, expectations, and implicit associations with high academic achievement compared to those exposed to cues indicating institutional chilliness. Exploring the phenomenology underlying these effects, Experiment 3 demonstrated that warmth cues led low-SES students to perceive their socioeconomic background as a better match with the rest of the student body and to perceive the university as more socioeconomically diverse than did chilliness cues. Contributions to our understanding of low-SES students' psychological experiences in academic settings and practical implications for academic institutions are discussed.
\end{abstract}

Keywords: socioeconomic status; institutional climate; academic motivation; academic self-concept. 


\section{The Effects of a Warm or Chilly Climate towards Socioeconomic \\ Diversity on Academic Motivation and Self-Concept}

Across nations and levels of education, persistent academic achievement gaps exist between students from high and low socioeconomic status (SES) backgrounds. In the United States, for example, low-SES students are about five times more likely than their higher-SES peers to drop out before graduating high school (Chapman, Laird, \& Remani, 2011) and 30\% less likely to apply to post-secondary education if they do complete high school (Baum, Ma, \& Payea, 2013). Furthermore, between 1992 and 2004, the gap in university acceptance rates between qualified high- and low-SES students increased by 14\% (Hull, 2010). Because only a select group of low-SES students are able to overcome the odds and reach the university level, one might expect that those who do enter university — defined here as any bachelor's degreegranting institution —-would generally perform well therein. However, recent reports suggest that this is not the case: low-SES university students in the United States are as many as eight times less likely to graduate than their higher-SES peers (Ishitani, 2006; Rumberger, 2010) and similar patterns emerge in many other Western industrialized countries (OECD, 2014).

A growing body of research has begun to examine a variety of social psychological mechanisms underlying the socioeconomic achievement gap in higher education (Croizet \& Claire, 1998; Harackiewicz et al., 2014; Johnson, Richeson, \& Finkel, 2011; Jury, Smeding, \& Darnon, 2015; Rheinschmidt \& Mendoza-Denton, 2014; Smeding, Darnon, Souchal, ToczekCapelle, \& Butera, 2013; Stephens, Fryberg, Markus, Johnson, \& Covarrubias, 2012; Stephens, Hamedani, \& Destin, 2014). This paper builds upon these emerging frameworks by investigating an underexplored potential contributor: how the perception of a "warm" versus "chilly" institutional climate towards socioeconomic diversity at a university influences the academic motivation and self-concepts of low-SES university students. Specifically, three experiments 
examine the effects of framing a university as openly supportive versus passively neglectful towards students from diverse socioeconomic backgrounds on the academic motivation, selfconcepts, and phenomenological experiences of low-SES students.

\section{Warm and Chilly Institutional Climates Towards Socioeconomic Diversity}

Low-SES students and their families often face significant difficulties in financing a university education (see Bowen, Kurzweil, \& Tobin, 2006; OECD, 2014). While providing financial resources is therefore unquestionably important for addressing these material disadvantages, financial support can also offer psychological benefits. For example, prior research has found that low-income middle school students who are led to believe that financial aid to attend university is readily available expect higher grades and plan to spend more time on homework than those who are simply reminded of the high costs of attending university (Destin \& Oyserman, 2009). In other words, the academic motivation and self-concepts of low-SES preuniversity students may be sensitive to whether higher education institutions seem to be supportive of students like them.

The present research examines whether a similar process occurs for students at the university level. Specifically, we propose that the perception of a "warm" versus "chilly" university climate towards socioeconomic diversity may influence the academic motivation and self-concepts of low-SES university students. Prior research defines a "chilly" (versus "warm”) academic climate as one where students from a particular group feel that their needs are ignored or overlooked by their institution and its constituents (Flam, 1991; Hall \& Sandler, 1982). We adopt this terminology in the present work because this theme of feeling ignored or overlooked in the university context frequently emerges when low-SES students discuss whether their academic institutions are supportive of their financial situations. In numerous open-ended interviews and focus group sessions, low-SES students have expressed that many universities' 
financial aid policies are inadequate for addressing the specific needs of students like them, with the inadequacy of work and scholarship opportunities being a common complaint (Baker \& Sgoutas-Emch, 2014; Somers \& Cofer, 1997; Ziskin, Fischer, Torres, Pellicciotti, \& PlayerSanders, 2014):

Financial Aid is a stressor. [...] When they [the university] offer you an amount that is not even close to what you expect, you have to spend the entire summer fighting just to get enough to stay on campus, let alone to get help with books and all the other stuff (Baker \& Sgoutas-Emch, 2014, p. 124).

Implicit in such reports is the sentiment that many low-SES students come to perceive their universities as not being committed to helping support students like them. In fact, many low-SES students express this sentiment directly:

It's great that measures are being taken to admit us. [...] But once we get here, we're left out in the cold. A little more effort to make this a place that is not just catered toward the wealthy [...] would go a long way (Class Confession \#491, 2014).

In other words, as this student makes clear, many low-SES students may experience their university climate as chilly, and thereby feel out of place in that context (Flam, 1991; Hall \& Sandler, 1982).

The readiness and frequency with which this theme emerges (Baker \& Sgoutas-Emch, 2014; Somers \& Cofer, 1997; Ziskin et al., 2014) is crucial, as in recent years, researchers have revealed how social psychological factors that lead low-SES students to feel out of the place can contribute to the socioeconomic achievement gap. Some relevant factors that have emerged include one's sense of social belonging and their vulnerability to experiencing social identity threat in the university context. For example, students from low-SES backgrounds have been 
found to underperform academically when they perceive that they are different from the majority of university students (Johnson et al., 2011; Ostrove \& Long, 2007), when they expect to be socially excluded on campus (Rheinschmidt \& Mendoza-Denton, 2014), and when they worry about being perceived as unintelligent (Croizet \& Claire, 1998; Spencer \& Castano, 2007). Indeed, interventions can reduce socioeconomic disparities in academic outcomes by guiding students to perceive their differences as strengths rather than as deficits (Stephens et al., 2014), leveraging self-affirmation to promote a sense of social belonging and academic fit (Harackiewicz et al., 2014), and using downward social comparison to enhance students' perceived status and thereby buffer against status-based identity threats (Johnson et al., 2011). Furthermore, low-SES and first-generation ${ }^{1}$ university students encounter specific issues of cultural mismatch because universities endorse and perpetuate independent cultural norms and values, which fit better with the norms and values shared by dominant high-status groups than with the more interdependent-focused ones associated with low-SES students' family backgrounds (Stephens et al., 2012). Indeed, reading a standard welcome letter promoting the school's focus on independent values (e.g., "learning by exploring your own interest) hindered first-generation students' performance on a subsequent academic tasks compared with those for whom the university environment was presented as embracing more interdependent cultural values (e.g., "learning by being part of a community").

In addition to these interpersonal, self-oriented, and cultural antecedents, recent research has demonstrated that structural elements of the university itself can also contribute to low-SES students' academic outcomes. For example, researchers have noted that specific structural elements like how the institution defines the function of its instructors ("[psychology] teachers do their best, throughout their practices, to identify the best students among you — those who deserve the most to become a psychologist" versus "to help students become psychologists"; 
Jury et al., 2015) and its student assessment practices ("this test will [...] identify differences in abilities" versus "this test will help you to reactivate your knowledge [...] and to identify elements that must be improved"; Smeding et al., 2013) can influence academic outcomes of low-SES students. Specifically, given that low-SES students are susceptible to experiencing threat in academic contexts (e.g., Croizet \& Claire, 1998; Spencer \& Castano, 2007), attending an institution that appears structured in a way that favors dominant group members (i.e., to select out weaker students) can hinder their academic performance compared to when the structure is a better fit for lower-status students (i.e., promotes learning; Jury et al., 2015; Smeding et al., 2013).

In other words, low-SES students' academic outcomes can be influenced by whether their university's policies appear to fit with or passively disregard the instruction and assessment styles favored by low-status students (Jury et al., 2015; Smeding et al., 2013). Building directly on this structure-focused perspective, we propose that the institutional climate toward socioeconomic diversity may represent a distinct structural element with implications for lowSES university students. In other words, institutions in which low-SES students expect to be supported or encounter difficulty in securing adequate work or financial aid opportunities (Baker \& Sgoutas-Emch, 2014; Somers \& Cofer, 1997; Ziskin et al., 2014) will be seen, respectively, as having or lacking a structural framework for supporting students from socioeconomically diverse backgrounds, which could similarly influence their academic outcomes. Examining the psychological influences of this largely unexplored factor is therefore critical to extending our understanding of the structural elements that contribute to low-SES students' experiences in the university setting.

In targeting the institutional climate, this approach complements yet remains distinct from prior empirical efforts. For example, in a recent intervention study, first- and continuing- 
generation student panelists described to participants their differences in how they adjusted to academic life at their university (Stephens et al., 2014). Such information certainly hinted that socioeconomic diversity was acknowledged at their institution, but ultimately focused more explicitly on showing students how to leverage their different backgrounds as a resource rather than explicitly framing the institutional climate as supportive toward socioeconomic diversity. In addition, some of the other approaches discussed previously have focused more directly on changing students' perceptions of certain aspects of the university context, such as the institution's structure regarding selection (Jury et al., 2015; Smeding et al., 2013) and its cultural norms (Stephens et al., 2012), but none have examined the role of the institutional climate towards socioeconomic diversity. The present studies therefore extend the existing literature by examining the unexplored and complementary potential influence of cues that explicitly suggest greater institutional warmth or chilliness towards socioeconomic diversity, including explicit statements that exalt or downplay the institution's commitment to financial aid and support for socioeconomically diverse students.

\section{The Influence on Students' Academic Motivation and Self-Concepts}

In addition to the previously discussed contribution, we note that much of the prior research has focused on identifying important social-psychological effects on low-SES students' achievement outcomes, such as performance on academic tasks and grades, with the underlying premise that processes like threat and cultural mismatch impair academic ability and functioning (Croizet \& Claire, 1998; Harackiewicz et al., 2014; Jury et al., 2015; Rheinschmidt \& MendozaDenton, 2014; Smeding et al., 2013; Stephens et al., 2012). In recent years, however, researchers have argued that performance impairments such as these may in fact represent shifts in motivation away from the present tasks and goals and changes in the perceived self-relevance of those goals (see Inzlicht \& Schmeichel, 2012; Kurzban, Duckworth, Kable, \& Myers, 2013). In 
other words, feeling out of place in the academic context may shift a student's motivational priorities and self-concepts away from academic tasks and goals. However, the motivational and self-concept-relevant influences of the institutional climate have yet to be examined. In the current research, we therefore focus on how presenting an institution's climate as chilly or warm can influence both low-SES students' motivation to pursue academic goals and their academic self-concepts, or the sense of connection between their own personal identity and academic goals.

We draw from key principles of identity-based motivation theory. In line with the motivational and self-relevant shift perspective, this theory predicts that a person's sense of what they are capable of in a certain domain is highly sensitive to situational context. Specifically, if situational cues suggest that a domain-relevant context is a good (versus poor) match for a person, that individual will feel more confident in that domain and more efficacious and ready to pursue domain-relevant goals (i.e., greater domain-relevant motivation), as well as a stronger sense of personal connectedness to success in that domain (i.e., greater inclusion of domainrelevant success in the self-concept; see Oyserman, 2013; Oyserman \& Destin, 2010). We therefore propose that cues which suggest that an educational institution is explicitly committed to or passively ignoring of socioeconomic diversity (i.e., is warm or chilly) may exert parallel effects on the academic motivation and self-concepts of low-SES students. As such, if an academic institution seems prepared to support the needs of socioeconomically diverse students, low-SES students in that context should feel more academically efficacious (see Schunk, 1991), set higher academic expectations (Destin \& Oyserman, 2009), and experience a stronger sense of connection between their own personal identity and high academic achievement (Ramsey, Betz, \& Sekaquaptewa, 2013; Stout, Dasgupta, Hunsinger, \& McManus, 2011) than they would if their institution appeared less supportive. 
Prior research examining other marginalized groups lends some support for these predictions. For example, female STEM students whose programs were explicitly dedicated to offering academic resources and social support for women entering STEM fields showed stronger implicit identification with STEM than those whose programs did not provide such supportive messages (Ramsey et al., 2013). Likewise, minority workers reported greater domainrelevant engagement when their majority group co-workers valued diversity, compared to settings where they valued color-blindness (i.e., ignored group differences; Plaut, Thomas, \& Goren, 2009). In summary, the current approach builds upon an emerging understanding of the structural institutional factors that can influence the ability of low-SES students to succeed by investigating how the perceived institutional climate towards socioeconomic diversity might influence these students' academic motivation (i.e., academic efficacy and expectations) and self-concepts (i.e., implicit association with high academic achievement).

\section{Overview of Experiments}

Three experiments examine whether the presence of cues suggesting an institution's commitment to versus passive ignoring of socioeconomic diversity can influence the academic motivation and self-concepts of low-SES university students. Experiments 1 and 2 manipulate the framing of the institutional climate towards socioeconomic diversity to test our hypothesis that low-SES students exposed to cues suggestive of institutional warmth can lead to greater academic efficacy, academic expectations, (Experiment 1) and implicit association with high academic achievement (Experiment 2) compared to those exposed to cues indicating institutional chilliness. In other words, these studies were designed to compare the effects of two institutional climate framings on low-SES university students' academic motivation and self-concepts.

Finally, in a third study (Experiment 3), we attempt to gain a better understanding of how lowSES students experience and are influenced by warm and chilly institutional cues. Specifically, 
Experiment 3 examines how such cues influence several psychological constructs that have been connected to academic outcomes among low-SES and other minority students in prior research, including perceived numerical representation of one's group (e.g., Murphy, Steele, \& Gross, 2007; Purdie-Vaughns, Steele, Davies, Ditlmann, \& Crosby, 2008), perceptions of match between one's socioeconomic background and that of the rest of their university's student body (Johnson et al., 2011; Ostrove \& Long, 2007), and feelings of and concerns regarding social belonging (Harackiewicz et al., 2014; Rheinschmidt \& Mendoza-Denton, 2014; Walton \& Cohen, 2007).

\section{Experiment 1}

Experiment 1 tests whether the framing of the institutional climate towards socioeconomic diversity affects student motivation. Using statements that exalt or downplay the institution's commitment to supporting socioeconomic diversity, Experiment 1 manipulates the framing of the university climate as either warm or chilly and assesses its effects on the academic efficacy and expectations of low- and high-SES students attending that university.

\section{Method}

Before beginning data collection, we estimated the sample size necessary to achieve a power level of .80 for a medium-sized effect. Indicating that we were testing for a significant interaction term (condition $\times$ SES) in a three-predictor regression model, the analysis (using

G*Power; Faul, Erdfelder, Buchner, \& Lang, 2009) revealed an $N_{\text {minimum }}$ of 55 . We then planned to collect data for full academic quarters until this sample size requirement had been surpassed. Data collection for Experiment 1 was ceased after one quarter, by which time 76 undergraduate students from a medium-sized Midwestern American university had participated for course credit (see Table 1 for complete demographics). Pre-testing $(N=1,257)$ revealed that this institution had a predominantly wealthy student body — the median household income of 
students' families was in the range of $\$ 120,000-\$ 150,000$, compared with the population median of $\$ 51,939$ (U.S. Census Bureau, 2014). In addition, it had an extensive financial aid program, participated in the Federal Work-Study program, and advertised in its promotional materials that it "prides itself on the personal attention it provides to each financial aid applicant" (Office of Undergraduate Admission, 2014, p. 2). As such, depending on which cues were made salient, the institutional climate could be presented as either welcoming or neglectful toward socioeconomic diversity. Analyses were not conducted prior to collection of the full sample.

As in prior research examining university students (e.g., Johnson et al., 2011;

Rheinschmidt \& Mendoza-Denton, 2014), SES was operationalized as family income. To that end, as part of a mass pre-testing session, students reported their family's household income from a list of nine categories: (1) $\$ 25,000$ or less, (2) $\$ 25,001-\$ 40,000$, (3) $\$ 40,001-\$ 70,000$, (4) $\$ 70,001-\$ 90,000,(5) \$ 90,001-\$ 120,000,(6) \$ 120,001-\$ 150,000,(7) \$ 150,001-\$ 200,000,(8)$ $\$ 200,001-\$ 300,000$, and (9) $\$ 300,001$ or more $(M=4.08, S D=2.18)^{2}$

Participants then attended a lab session at least five weeks following pre-testing, at which time they were told that they would be completing two short studies. For the first study, they completed a survey that they were told was being conducted in conjunction with the admissions office at their university, which was designed to gather students' opinions on promotional materials that the school was considering using to recruit future undergraduates. To corroborate this cover story, all participants were first presented with two standard promotional statements regarding their school: "[School name] has over 80 majors and 4,000 classes" and "[School name] is recognized both nationally and internationally for the quality of its educational programs at all levels. U.S. News \& World Report consistently ranks the university's undergraduate programs among the best in the country." 
The next two statements presented served as the manipulation of the framing of the institution's climate regarding socioeconomic diversity. Specifically, students randomly assigned to the chilly climate condition were presented with two statements that framed their university environment as being a predominantly high-SES context which passively ignores the presence and needs of lower-SES students: "The cost of attendance for the 2011-12 academic year was $\$ 58,429$, which over half of [school name] families managed without any financial aid" and "In 2011, parents of [school name] students and alumni gave more than $\$ 1.8$ million to bolster the school's endowment through the Parents' Fund, with gifts ranging up to $\$ 250,000$. With their help, [school name] has maintained the 9th largest endowment in the nation, surpassing \$7 billion in 2010-2011." The meta-message in this condition was that the university is focused on serving students from wealthy families. By contrast, participants assigned to the warm climate condition instead saw two statements that presented the context as committed to promoting socioeconomic diversity: "Dedicated to assisting students in earning money to meet their educational costs, [school name] is strongly involved with the Federal Work-Study program. [School name] will pay over \$2.8 million to its Work-Study students this year" and "[School name] has an extremely far-reaching financial aid program, with $60 \%$ percent of all [school name] undergraduates receiving financial aid." The meta-message in this condition was that the university is committed to serving students from all socioeconomic backgrounds. Finally, to corroborate the cover story that the institution was collecting students' view on these statements, participants were asked to arrange the four statements in the order they thought they should appear in any promotional materials that would be presented to the general public.

Following the manipulation, participants were told that they would now be continuing to the second study, which was a series of academic questionnaires. First, participants' academic expectations were assessed by having them report the grade point average (out of 4.0) they 
expected to have when they graduated $(M=3.53, S D=.33$; e.g., Destin \& Oyserman, 2009). Next, academic efficacy was assessed using the following five-item scale: "I can do even the hardest work at [school name] if I try"; "I'm certain I can figure out how to do the most difficult class work"; "I'm certain I can master the skills taught at [school name] this upcoming year"; "When I experience challenges at [school name], I will have no problem asking for help"; and "I can do all of the work in class if I don't give up" (adapted from Midgley et al., 2000).

Participants responded using a 1-7 scale ranging from "strongly disagree" to "strongly agree" ( $M$ $=5.14, S D=1.04, \alpha=.79)$. Finally, participants reported their current GPAs $(M=3.44, S D=$ .42) to allow us to test whether random assignment was effective. No cover story was presented for this "second study."

\section{Results and Discussion}

Twelve participants did not report their family's household income. Random assignment was effective: there were no between-condition differences in income (warm climate condition: $M=3.97, S D=2.33$; chilly climate condition: $M=4.21, S D=2.01$ ) or current GPA (warm climate condition: $M=3.45, S D=.39$; chilly climate condition: $M=3.43, S D=.45), p \mathrm{~s}>.66$.

To examine the effects of the institutional climate regarding socioeconomic diversity on low- and high-SES students, students' academic efficacy scores and expected graduating GPAs were independently regressed on condition, income (mean-centered), and their interaction. This analysis revealed significant interaction terms predicting both efficacy and expected graduating GPA (see Table 2 and Figure 1). In addition, the simple effects of condition on academic efficacy (with the chilly and warm climate conditions coded as -1 and 1 , respectively) were significant and positive among low-SES students (-1 SD in income), and non-significant among their high-SES counterparts (+1 SD in income; see Table 2). The patterns of the simple effects of condition on students' expected graduating GPAs were similar, but neither reached significance 
(see Table 2). In other words, low-SES students reported lower levels of academic efficacy and (non-significantly) lower expected graduating GPAs when the institution was not presented as being structured to support low-SES students compared to when it was framed as being supportive of socioeconomic diversity, while no between-condition differences emerged among their high-SES peers. ${ }^{3}$

\section{Experiment 2}

Building from the results of Experiment 1, the goal of Experiment 2 was to examine how cues about the institutional climate towards socioeconomic diversity influence low-SES students' academic self-concepts, or the sense of connection between their own personal identity and high academic achievement (see Oyserman, 2013; Oyserman \& Destin, 2010). While Experiment 1 revealed effects using self-report measures of academic motivation, prior research suggests that examining one's personal connectedness to a goal domain (e.g., high academic achievement) may require a more implicit approach. Specifically, while contextual cues are known to produce substantial shifts in people's working self-concepts (see Markus \& Wurf, 1987; McConnell, 2011; Oyserman, 2013; Oyserman \& Destin, 2010), studies have found that these shifts may be observable only when the self-concept is examined indirectly. In a seminal demonstration, Markus and Kunda (1986) found that while people's explicit self-descriptions did not vary as a result of situational manipulations, the strength of their self-associations (i.e., response latencies) did. As such, the authors concluded that "very general self-descriptive measures are inadequate for revealing how the individual adjusts and calibrates the self-concept in response to challenges from the social environment" (p. 858). In addition, studies have found that the effects of subtly manipulating gender representation cues in STEM environments (e.g., advertising a math department event featuring more or less female professors, or encountering an advanced female or male math student) were observable with implicit but not explicit measures of STEM 
identification (Ramsey et al., 2013; Stout et al., 2011). Experiment 2 therefore assesses whether low-SES students' level of implicit association with high academic achievement can be influenced by whether or not their university environment is framed as supportive of students from their socioeconomic background.

\section{Method}

Following Experiment 1, we originally planned to collect data for one academic quarter. While the results of interest were significant thereafter, our sample size did not reach the minimum suggested by the a priori power analysis (see Experiment 1). We therefore continued collecting participants for an additional academic quarter, after which we had surpassed that threshold. The final sample consisted of 130 undergraduate students from the same Midwestern American university as in Experiment 1 (see Table 1 for complete demographics).

First, either at a mass pre-testing session or in an online pre-testing survey, participants reported their family's household income using the same measure used in Experiment $1(M=$ $5.69, S D=2.64)$. At a separate lab session, participants were then randomly assigned to the same warm and chilly climate manipulation conditions employed in Experiment 1 . Consistent with prior research, implicit association with high academic achievement was then measured using an implicit association test (IAT), which assessed how quickly participants categorized stimuli related to high achievement (honors, Dean's list, top 5\%, success, $A+, 4.0$ GPA) versus low achievement (probation, drop out, bottom 5\%, failure, D-, 1.0 GPA) and items that represented the self (I, me, my, mine) versus others (they, them, their, theirs; for details, see Devos \& Cruz Torres, 2007; Nosek, Banaji, \& Greenwald, 2002). Participants completed seven blocks of trials: three practice blocks consisting of 20 trials each, and four critical blocks consisting of 40 trials each. Finally, participants again reported their current GPAs $(M=3.40, S D=.41)$.

\section{Results and Discussion}


Random assignment was effective: there were no between-condition differences in income (warm climate condition: $M=5.94, S D=2.77$; chilly climate condition: $M=5.50, S D=$ 2.55 ) or current GPA (warm climate condition: $M=3.43, S D=.44$; chilly climate condition: $M=$ 3.37, $S D=.38), p s>.36$. Implicit associations with high academic achievement were calculated by subtracting the mean latencies for $I+$ low achievement $\mid$ they + high achievement block responses from those for $I+$ high achievement $\mid$ they + low achievement block responses and dividing by the pooled (i.e., across-condition) standard deviation for those blocks (for details, see Lane, Banaji, Nosek, \& Greenwald, 2007, Table 3.3). This calculation was performed after checking for critical trials with response latencies greater than $10,000 \mathrm{~ms}$ ( 0 trials) and removing the data of participants for whom more than $10 \%$ of their critical trials had latencies less than $300 \mathrm{~ms}$ ( 1 participant, with $53.6 \%$ of trials below $300 \mathrm{~ms}$ ). Positive scores indicate stronger implicit association with high academic achievement. The data of 11 other participants could not be included in the main analyses - five whose IAT data were not recorded due to technical difficulties, and six whose remaining lab data were not recorded due to technical difficulties.

To test whether low-SES students would display lower levels of implicit association with high academic achievement when the university climate was framed as chilly with regard to socioeconomic diversity compared to when it was instead presented as warm, implicit association scores were regressed on condition, income (mean-centered), and their interaction (see Table 3). The interaction was significant (see Figure 2), and breaking this term down revealed that the simple effect of condition on implicit association scores (with the chilly and warm climate conditions coded as -1 and 1 , respectively) was significant and positive among low-SES students (-1 SD in income), and non-significant among their high-SES counterparts $(+1$ $S D$ in income; see Table 3). In other words, the strength of low-SES students' implicit associations with high academic achievement were weaker when the institution was not 
presented as being structured to support low-SES students compared to when it was framed as being supportive of socioeconomic diversity. Again, no between-condition differences emerged among their high-SES peers. ${ }^{4}$

\section{Experiment 3}

Experiments 1 and 2 support our contention that the presence of cues suggestive of a university's diverse socioeconomic demography and commitment to promoting socioeconomic diversity can influence the academic motivation and self-concepts of low-SES university students. The goal of Experiment 3 was to examine the phenomenology associated with these framing effects. In other words, among our low-SES participants, what psychological constructs are being affected by these warm and chilly institutional cues? To examine this, we exposed participants to the same manipulation before collecting data on a nomological net of variables that are central to the psychological experiences of minority group members in majoritydominated domains. Specifically, we assessed three factors that have been shown to influence academic outcomes among low-SES and other minority students: perceived numerical representation of one's group in domain-relevant settings (e.g., Murphy et al., 2007; PurdieVaughns et al., 2008), perceptions of match between one's socioeconomic background and that of the rest of their university's student body (Johnson et al., 2011), and feelings of and concerns regarding social belonging (Harackiewicz et al., 2014; Walton \& Cohen, 2007).

\section{Method}

Participants completed Experiment 3 as part of an online pre-screening survey for an unrelated study. This survey was available for participants to complete for one academic quarter. In keeping with the minimum sample size recommendations culled from an a priori power analysis (see Experiment 1), 131 undergraduate students from the same Midwestern American 
university as in Experiments 1 and 2 completed Experiment 3 within this time frame (see Table 1 for complete demographics). Analyses were not conducted prior to collection of the full sample.

Participants began by responding to a basic demographics questionnaire, embedded in which was the same measure of family household income used in Experiments 1 and $2(M=$ $5.18, S D=2.27)$. Participants then completed several unrelated filler questions before being randomly assigned to the same warm and chilly climate conditions used in Experiments 1 and 2.

To test whether the warm and chilly climate conditions were effectively altering students' perceptions of how committed their university was to promoting socioeconomic diversity (i.e., a manipulation check), participants responded to a two-item measure that we created: "I feel that [school name] is committed to promoting socioeconomic diversity within its student body" and "I feel that [school name] cares about all its students and applicants equally, regardless of their social class background" $(M=4.16, S D=1.48, r(129)=.55, p<.001)$. Responses to this measure and all measures that follow (unless otherwise indicated) were provided using a 7-point scale, ranging from "strongly disagree" to "strongly agree."

To determine the effects of the warm and chilly climate conditions on variables that are relevant to the psychological experiences of low-SES and other minority students, participants completed four measures. First, as a measure of students' perceptions of their SES group's numerical representation at their university, they were asked, "What percentage of [school name] students do you think come from each of these socioeconomic backgrounds? (1) Lower-class and working-class $(M=26.5 \%, S D=13.4 \%)$; (2) Middle-class and upper-class.” The summed percentages had to equal $100 \%$ for participants to be able to continue to the next section. ${ }^{5}$ Second, as an indicator of their sense of match/mismatch between their socioeconomic background and the institutional context, participants completed the Sensitivity to SES-based Identity Discrepancy scale (SSID; Johnson et al., 2011). Items included "I come from a very 
different socioeconomic background than most [school name] students" and "My family background/upbringing is similar to that of the typical [school name] student" (reverse-scored; $M$ $=4.09, S D=1.44, \alpha=.91$; see supplemental materials for the complete scale). Third, perceptions of social belonging at their institution were assessed using a one-item measure used in prior research (Walton \& Cohen, 2007; Harackiewicz et al., 2014): “I feel that I belong at [school name]" $(M=5.10, S D=1.38)$. Finally, social belonging concerns were assessed with a two-item measure of belonging uncertainty used in prior research (Walton \& Cohen, 2007; Harackiewicz et al., 2014): “Sometimes I feel that I belong at [school name], and sometimes I feel that I don't belong" and "When something bad happens, I feel that maybe I don't belong at [school name]" $(M=4.54, S D=1.44), r(125)=.48, p<.001$. Finally, participants again reported their current GPAs $(M=3.51, S D=.38)$.

\section{Results and Discussion}

Random assignment was effective: no between-condition differences emerged in terms of income (warm climate condition: $M=4.91, S D=2.16$; chilly climate condition: $M=5.45, S D=$ 2.36) or current GPA (warm climate condition: $M=3.49, S D=.36$; chilly climate condition: $M=$ $3.54, S D=.41), p \mathrm{~s}>.17$. Table 4 presents the correlations between our variables of interest. With the exception of the strong negative relationship between income and SSID (see also Johnson et al., 2011, Study 1), the correlations were generally small to medium, suggesting that our measures were assessing relatively different constructs.

To test whether the warm and chilly climate conditions were in fact altering low-SES students' perceptions of how committed their university was to promoting socioeconomic diversity, participants' responses to our manipulation check measure were regressed on condition, income (mean-centered), and their interaction (see Table 5). There was a marginal main effect of condition, such that those in the warm climate condition perceived the institution 
to be more committed to supporting socioeconomic diversity than did those in the chilly climate condition. In addition, a marginal interaction term emerged, such that low-SES students (-1 SD in income) in the warm climate condition reported greater perceived commitment than those in the chilly climate condition (see Table 5). By contrast, there was no effect of condition on perceived commitment among high-SES students (+1 SD in income; see Table 5). In other words, our manipulations effectively influenced low-SES students' beliefs regarding their institution's level of commitment to supporting socioeconomically diverse students.

Again, the primary goal of Experiment 3 was to determine whether framing the university climate as warm versus chilly could influence a nomological net of variables that are central to the academic experiences of minority group members. To test this, our four dependent variables of interest - participants' estimates of the percentage of students from lower-class and workingclass backgrounds, SSID, belonging uncertainty, and perceived belonging at university—were separately regressed on condition, income (mean-centered), and their interaction. The interaction terms for two of the dependent variables - numerical representation of students from lower-class and working-class background, and SSID_were significant and marginal, respectively (see Table 5). In addition, simple slope analyses (see Table 5) revealed that compared to those in the chilly climate condition, low-SES students in the warm climate condition reported significantly higher estimates of the number of low and working class students at their institution, and saw themselves as marginally less discrepant from the SES norms of the university context. No between-condition differences emerged among higher-SES students for either of these dependent measures. In addition, no significant effects emerged regarding students' sense of or uncertainty regarding social belonging at university. ${ }^{6}$

These findings suggest that cues implying that the institutional climate is warm or chilly towards socioeconomic diversity do, in fact, influence low-SES students' perceptions of their 
university's commitment to socioeconomic diversity and, ultimately, the perceived prevalence of this diversity and their sense of how well they match the SES norms of their university's student body. By contrast, students' feelings of and concerns regarding social belonging did not appear to be influenced by such cues. In other words, while social belonging at university can be a central concern with deep implications for academic outcomes among low-SES and other minority students (Harackiewicz et al., 2014; Rheinschmidt \& Mendoza-Denton, 2014; Walton \& Cohen, 2007), the results of Experiment 3 suggest that students' perceptions of where the institution itself stands on issues of socioeconomic diversity and financial support may be another distinct mechanism to target. ${ }^{7}$

\section{General Discussion}

Qualitative research efforts have revealed that many low-SES students perceive their academic institutions as not being concerned with supporting students like them, with the inadequacy of work and scholarship opportunities being a common complaint (Baker \& SgoutasEmch, 2014; Somers \& Cofer, 1997; Ziskin et al., 2014). As feeling that one's needs are ignored or overlooked by an institution can have significant implications for domain-relevant motivation and self-concepts (e.g., Murphy et al., 2007; Purdie-Vaughns et al., 2008; Ramsey et al., 2013), we conducted three experiments to examine whether presenting a university as being warm and supportive of socioeconomic diversity could enhance the academic motivation and self-concepts of low-SES students compared to when the institution is framed as chillier in that respect. Experiments 1 and 2 found that exposing low-SES students to cues suggestive of their university's commitment to supporting socioeconomic diversity (via financial aid and work opportunities) lead to greater confidence in pursuing academic tasks, higher expectations for academic success, and stronger implicit associations with high academic achievement compared to when the institution seemed less concerned with supporting low-SES students. Exploring the 
phenomenology of these effects, Experiment 3 found that framing the university climate as warm versus chilly influenced low-SES students' perceptions of the prevalence of socioeconomic diversity at their university and their sense of match between their own socioeconomic background and the student body at-large. By contrast, no between-condition differences emerged among high-SES students in any of our studies. An academic institution's climate towards supporting socioeconomically diverse students therefore appears to be an important determinant of the academic motivation and self-concepts of low (but not high) SES university students.

\section{Theoretical Implications}

The current work has several theoretical implications. Foremost, it extends the empirical conversation regarding the influences of structural elements of the academic environment for low-SES students. As discussed, prior research has found that specific structural factors, such as whether or not an institution appears to be organized primarily to select out weaker students from the system (Jury et al., 2015; Smeding et al., 2013), can influence the academic outcomes of lowSES university students. The present research proposed that the institutional climate toward socioeconomic diversity represents another essential structural element with related academic implications. Indeed, our three experiments suggest that institutions that appear to lack a structural framework for supporting students from socioeconomically diverse backgrounds, such as those in which low-SES students encounter difficulty in securing adequate work or financial aid opportunities, can hinder the academic motivation and self-concepts of its low-SES students compared to those that are seen as supportive. Critically, this structural element may influence students even before they reach university, as prior research has found that low-income middle students who believe that university financial aid is readily available expect higher grades and plan to spend more time on homework than those who were simply reminded how expensive 
university is (Destin \& Oyserman, 2009). In other words, across levels of schooling, the academic outcomes of low-SES students may be sensitive to whether their current or future university world appears to be structured to support students like them.

Furthermore, this research extends upon the numerous studies demonstrating important social-psychological effects on the academic performance of low-SES students (e.g., Croizet \& Claire, 1998; Harackiewicz et al., 2014; Rheinschmidt \& Mendoza-Denton, 2014; Smeding et al., 2013; Stephens et al., 2012) by shifting the focus to key motivational and self-conceptrelevant processes. Such advances are crucial, as examining these processes may be imperative for achieving a complete understanding of how SES influences academic outcomes. For example, one extension of the social identity threat perspective discussed previously proposes that seeing one's socioeconomic background as mismatched with that of the rest of their university's student body may deplete low-SES students' limited self-regulatory resources (Johnson et al., 2011), thereby undermining their academic performance (Croizet \& Claire, 1998; Spencer \& Castano, 2007). From this view, self-regulatory resource depletion is proposed as the mechanism by which SES influences academic outcomes (Johnson et al., 2011). As discussed, however, in recent years, researchers have argued that such depletion may in fact represent shifts in motivation away from the present tasks and goals and changes in the perceived self-relevance of those goals (see Inzlicht \& Schmeichel, 2012; Kurzban et al., 2013). In other words, our understanding of the causal path from SES to performance through self-regulation may be strengthened by the inclusion of motivational and self-concept-centered factors explaining the initial link between SES and self-regulation. Future efforts to model the relationship between SES and academic performance might therefore seek to build from the present findings.

Finally, the lack of effects among high-SES students is also noteworthy. Given prior findings regarding dominant group members' responses to multiculturalism and diversity 
policies (see Verkuyten, 2006), it seemed plausible that presenting their university as being committed to promoting socioeconomic diversity could negatively influence the psychological experiences of high-SES students. However, the null results among these students in Experiments 1 and 2 suggest that compared to when their university was framed as having a high-SES-focused structure (i.e., the chilly climate condition), presenting the context as being structured to promote socioeconomic diversity (i.e., the warm climate condition) did not have any negative effects on their academic outcomes. These findings are supported by prior work examining structural factors in the university environment, as Smeding and colleagues (2013) similarly found that the academic outcomes of high-SES students were not influenced by whether an institution appeared structured primarily to select out weaker students from the system, which favors dominant group members, or to promote learning in all students, which supports the needs of lower-status students. As to why these null effects emerge, an examination of the results of our manipulation check from Experiment 3 reveals that in both conditions, highSES students $(+1 S D)$ responded neutrally with regard to their perceptions of how committed their university was to promoting socioeconomic diversity (4.13 on a 7-point scale). In other words, high-SES students may generally be unaware of their university's policies towards socioeconomic diversity and may therefore not see the warm climate condition as suggesting any differences in the school's level of commitment thereto. However, our studies were not designed to provide an in-depth examination of the psychological experiences of high-SES students and future research on the effects of such structural changes on this group is therefore required.

\section{Practical Implications}

The present findings also have potential practical implications. Specifically, for institutions that already have the structural elements in place to support low-SES students (e.g., those that offer large amounts of financial aid and work opportunities, like the university we 
examined), our findings illuminate the importance of how such policies are presented. For example, in a recent and widely-circulated announcement regarding a major increase in the number of families qualifying for tuition-free admission, one American university followed their positive financial aid message by stating that only around half of their students receive financial aid, in spite of the fact that families with incomes up to $\$ 225,000$ could qualify for financial assistance. Given the present findings, it seems plausible that such details could counteract the potential positive effects that were intended to result from the increased support message and ultimately suggest to low-SES students that a majority of their peers come from families making more than $\$ 225,000$, thereby leading them to believe that the school may not be primarily concerned with the needs of low-SES students. In other words, while providing monetary resources is unquestionably important (Bowen et al., 2006), our work suggests that the way in which such policies are presented can have added implications for students' social-psychological resources.

The significance of our results for universities that do not have such policies in place remains an open question. On one hand, because it may be difficult to present an institution as warm when it lacks policies for promoting socioeconomic diversity, our findings suggest that such institutions may be more likely to be viewed as chilly, which should result in sub-optimal outcomes. By contrast, it seems plausible that the psychological importance of the climate towards socioeconomic diversity may be reduced at institutions that lack such policies but traditionally impose less financial burden on their students, such as larger public American universities (Rheinschmidt \& Mendoza-Denton, 2014), community colleges (Ziskin et al., 2014), and European universities (Smeding et al., 2013). Both of these possibilities are speculative, however, and should be the focus of future research.

\section{Future Directions}


Some additional questions remain. First, our studies did not include a control condition. As such, we acknowledge that this research does not enable us to determine whether the default climate at the institution we investigated trended towards being chilly or warm with regard to socioeconomic diversity, nor, as a result, whether changes in academic outcomes from baseline emerge when academic climates are warmed, chilled, or both. However, we note that these were not the goals of the present research. As discussed throughout, our studies were designed to test the more general social-psychological question of whether presenting the institutional climate as warmer towards socioeconomic diversity can lead to better academic outcomes among low-SES students compared to when the school is framed as being chillier in this regard. Given these goals, determining whether the climate at the institution we investigated is generally chilly, generally warm, or somewhere in between would have done little to enhance our understanding of the general psychological process of interest. Instead, we focused on exploring the basic dynamics and influences of this previously unexplored factor, with the aim of contributing to a more complete understanding of low-SES students' psychological experiences (and, potentially, achievement outcomes) in specific academic settings. In other words, just as we have discussed that future research is required to examine the implications of climate at institutions that do not have the resources in place for supporting low-SES students, we feel that the question of what the default climates and directions of post-manipulation change are at this and other types of institutions is broader than the present project was designed to explore. We feel that this question would be better suited to (and that the present research would be well complemented by) a more comprehensive follow-up project aimed at documenting the role of climate at different types of institutions with varying socioeconomic support structures in place.

Second, our studies presented cues representing only a single way of framing the institutional climate (i.e., warmth cues or chilliness cues). In the real world, however, students 
likely experience both types of cues everyday — for example, being in the vicinity of sorority and fraternity houses, versus seeing a long line-up at the financial aid office. Given that opposing situational cues can interact in important ways (e.g., Purdie-Vaughns et al., 2008), examining the types and quantities of SES-relevant cues that students experience on a daily basis and how they respond to and are influenced by such cues could provide valuable advances to our understanding of the longitudinal effects of the institutional climate on academic outcomes.

Third, as discussed, our research focused on documenting the effects of how an institution appears to be organized in terms of their commitment to supporting socioeconomic diversity - in other words, the effects of directly manipulating how a structural element of the institution is presented (see also Jury et al., 2015; Smeding et al., 2013). However, it seems plausible that perceptions of the institutional climate could also have roots in the cultural norms of the institution. Specifically, in the same way that cultural norms of independence and interdependence can lead school administrators to organize their classroom policies to provide ample versus limited individual freedom (for review, see Stephens, Markus, \& Phillips, 2014), whether an institution publicizes policies that frame it as actively committed to versus passively ignoring of socioeconomic diversity may result from the administration's beliefs regarding what should be normative in the university environment. In short, the institutional climate towards socioeconomic diversity may ultimately be the product of both structural and cultural elements, and future research should seek to extend our structure-focused approach by more directly examining the influence of institutions' cultural norms regarding socioeconomic diversity.

Fourth, in Experiment 3, we found that that belonging and belonging uncertainty among low-SES students were not influenced by cues related to the institution's socioeconomic climate. Given that social belonging at university can be a central concern with deep implications for academic outcomes among low-SES and other minority students (Harackiewicz et al., 2014; 
Rheinschmidt \& Mendoza-Denton, 2014; Walton \& Cohen, 2007), future research should seek to further understand and extend this finding. On one hand, because our manipulation materials focused on financial aspects of the university environment, it seems logical that students' immediate concerns might center on the general appropriateness of their SES background therein (Johnson et al., 2011), with the quality of their social bonds in that setting (e.g., Walton \& Cohen, 2007) thereby becoming a more secondary and less salient concern. However, this interpretation should be taken with caution until a more thorough investigation of students' belonging-relevant experiences is conducted. Specifically, while we assessed belonging and belonging uncertainty using validated measures that have seen extended use in similar research endeavors (Harackiewicz et al., 2014; Walton \& Cohen, 2007), the scales included only a small number of items, which might not provide optimal granularity, and other potentially relevant constructs were not examined (e.g., class-based rejection sensitivity; Rheinschmidt \& MendozaDenton, 2014). In addition, prior studies examining these interpersonal experiences have been largely longitudinal in nature (e.g., Harackiewicz et al., 2014; Walton \& Cohen, 2007)—a strategy which may be better able to capture these potentially secondary concerns as they emerge.

Finally, the samples utilized in the present work were predominantly White and Asian (see Table 1 for complete demographics) and were therefore inappropriate for exploring the effects among minority-race students - another group at risk for academic decrements (e.g., Steele, Spencer, \& Aronson, 2002; Walton \& Cohen, 2007). However, given that the negative effects of being low-SES reported herein resulted from whether the institutional climate was framed as warm or chilly with regard to socioeconomic diversity, it seems likely that the combined effects of SES and race on academic outcomes should similarly hinge on whether the 
climate is experienced as warm or chilly with regard to both socioeconomic and racial diversity (e.g., Purdie-Vaughns et al., 2008).

\section{Conclusion}

To date, the expansion of financial aid has been the primary means for addressing the socioeconomic disparities in university attendance and achievement (see Bowen et al., 2006). However, as recent findings suggest, the concept of equal opportunity in education also hinges heavily on creating educational environments that allow all capable students to showcase their

full potential (e.g., Jury et al., 2015; Smeding et al., 2013; Stephens et al., 2012). As our findings suggest, such ventures should consider the everyday presentation of the socioeconomic climate at academic institutions. 


\section{References}

Baker, M. A., \& Sgoutas-Emch, S. A. (2014). Evidence-Based Strategic Planning: Using Mixed Methods and the Social Ecological Model to Target Student Financial Stress. College Student Affairs Journal, 32(1), 113.

Baum, S., Ma, J., \& Payea, K. (2013). Education Pays: The Benefits of Higher Education for Individuals and Society. New York, NY: The College Board.

Bowen, W. G., Kurzweil, M. A., \& Tobin, E. M. (2006). Equity and excellence in higher education. Charlottesville, VA: University of Virginia Press.

Chapman, C., Laird, J., \& Remani, A. K. (2011). Trends in High School Dropout and Completion Rates in the United States: 1972-2009. Washington, D.C.: National Center for Education Statistics.

Class Confession \#491. (2014). Retrieved from http://web.archive.org/web/20150909221728/http://nuclassconfessions.tumblr.com/post/7 7143009471/if-it-werent-for-reading-some-of-these

Croizet, J. C., \& Claire, T. (1998). Extending the concept of stereotype threat to social class: The intellectual underperformance of students from low socioeconomic backgrounds. Personality and Social Psychology Bulletin, 24(6), 588-594. http://doi.org/10.1177/0146167298246003

Destin, M., \& Oyserman, D. (2009). From Assets to School Outcomes: How Finances Shape Children's Perceived Possibilities and Intentions. Psychological Science, 20(4), 414-418. http://doi.org/10.1111/j.1467-9280.2009.02309.x

Devos, T., \& Cruz Torres, J. A. (2007). Implicit identification with academic achievement among Latino college students: The role of ethnic identity and significant others. Basic 
and Applied Social Psychology, 29(3), 293-310.

http://doi.org/10.1080/01973530701503432

Faul, F., Erdfelder, E., Buchner, A., \& Lang, A.-G. (2009). Statistical power analyses using G* Power 3.1: Tests for correlation and regression analyses. Behavior Research Methods, 41(4), 1149-1160. http://doi.org/10.3758/BRM.41.4.1149

Flam, F. (1991). Still a “Chilly Climate” for Women? Science, 252(5013), 1604-6. http://doi.org/10.1126/science.252.5013.1604

Hall, R. M., \& Sandler, B. R. (1982). The Classroom Climate: A Chilly One for Women? Washington, D.C.: Association of American Colleges.

Harackiewicz, J. M., Canning, E. A., Tibbetts, Y., Giffen, C. J., Blair, S. S., Rouse, D. I., \& Hyde, J. S. (2014). Closing the Social Class Achievement Gap for First-Generation Students in Undergraduate Biology. Journal of Educational Psychology, 375-389. http://doi.org/10.1037/a0034679

Hull, J. (2010). Chasing the college acceptance letter: Is it harder to get into college? Alexandria, VA: Center for Public Education.

Inzlicht, M., \& Schmeichel, B. J. (2012). What is ego depletion? Toward a mechanistic revision of the resource model of self-control. Perspectives on Psychological Science, 7(5), 450463. http://doi.org/10.1177/1745691612454134

Ishitani, T. T. (2006). Studying attrition and degree completion behavior among first-generation college students in the United States. Journal of Higher Education, 77(5), 861-885. http://doi.org/10.1353/jhe.2006.0042

Johnson, S. E., Richeson, J. A., \& Finkel, E. J. (2011). Middle class and marginal? Socioeconomic status, stigma, and self-regulation at an elite university. Journal of Personality and Social Psychology, 100(5), 838. http://doi.org/10.1037/a0021956 
Jury, M., Smeding, A., \& Darnon, C. (2015). First-generation students' underperformance at university: the impact of the function of selection. Educational Psychology, 710. http://doi.org/10.3389/fpsyg.2015.00710

Kraus, M. W., \& Stephens, N. M. (2012). A road map for an emerging psychology of social class. Social and Personality Psychology Compass, 6(9), 642-656. http://doi.org/10.1111/j.1751-9004.2012.00453.x

Kurzban, R., Duckworth, A., Kable, J. W., \& Myers, J. (2013). An opportunity cost model of subjective effort and task performance. Behavioral and Brain Sciences, 36(06), 661-679. http://doi.org/10.1017/S0140525X12003196

Lane, K. A., Banaji, M. R., Nosek, B. A., \& Greenwald, A. G. (2007). Understanding and using the implicit association test: IV. What we know (so far) about the method. In B. Wittenbrink \& N. S. Schwarz (Eds.), Implicit measures of attitudes: Procedures and controversies (pp. 59-102). New York, NY: Guilford Press.

Lareau, A., \& Conley, D. (2008). Social class: How does it work? New York, NY: Russell Sage Foundation.

Markus, H. R., \& Kunda, Z. (1986). Stability and malleability of the self-concept. Journal of Personality and Social Psychology, 51(4), 858. http://doi.org/10.1037/00223514.51 .4 .858

Markus, H. R., \& Wurf, E. (1987). The dynamic self-concept: A social psychological perspective. Annual Review of Psychology, 38(1), 299-337. http://doi.org/10.1146/annurev.ps.38.020187.001503

McConnell, A. R. (2011). The multiple self-aspects framework: Self-concept representation and its implications. Personality and Social Psychology Review, 15(1), 3-27. http://doi.org/10.1177/1088868310371101 
Midgley, C., Maehr, M. L., Hruda, L. Z., Anderman, E., Anderman, L., Freeman, K. E., ... Urdan, T. (2000). Manual for the patterns of adaptive learning scales. Ann Arbor, MI: University of Michigan.

Murphy, M. C., Steele, C. M., \& Gross, J. J. (2007). Signaling Threat: How Situational Cues Affect Women in Math, Science, and Engineering Settings. Psychological Science, 18(10), 879. http://doi.org/10.1111/j.1467-9280.2007.01995.x

Nosek, B. A., Banaji, M. R., \& Greenwald, A. G. (2002). Math = male, me = female, therefore math $\neq$ me. Journal of Personality and Social Psychology, 83(1), 44. http://doi.org/10.1037/0022-3514.83.1.44

OECD. (2014). OECD Indicators: Education at a Glace 2014. http://dx.doi.org/10.1787/eag2014-en

Office of Undergraduate Admission. (2014). Financial Aid. Retrieved from http://bit.ly/1zFGM16

Ostrove, J. M., \& Long, S. M. (2007). Social class and belonging: Implications for college adjustment. Review of Higher Education, 30(4), 363-389. http://doi.org/10.1353/rhe.2007.0028

Oyserman, D. (2013). Not just any path: Implications of identity-based motivation for disparities in school outcomes. Economics of Education Review, 33, 179-190. http://doi.org/10.1016/j.econedurev.2012.09.002

Oyserman, D., \& Destin, M. (2010). Identity-based motivation: Implications for intervention. The Counseling Psychologist, 38(7), 1001-1043. http://doi.org/10.1177/0011000010374775 
Plaut, V. C., Thomas, K. M., \& Goren, M. J. (2009). Is Multiculturalism or Color Blindness Better for Minorities? Psychological Science, 20(4), 444-446. http://doi.org/10.1111/j.1467-9280.2009.02318.x

Preacher, K. J., \& Hayes, A. F. (2008). Asymptotic and resampling strategies for assessing and comparing indirect effects in multiple mediator models. Behavior Research Methods, 40(3), 879-891. http://doi.org/10.3758/BRM.40.3.879

Purdie-Vaughns, V., Steele, C. M., Davies, P. G., Ditlmann, R., \& Crosby, J. R. (2008). Social identity contingencies: how diversity cues signal threat or safety for African Americans in mainstream institutions. Journal of Personality and Social Psychology, 94(4), 615. http://doi.org/10.1037/0022-3514.94.4.615

Ramsey, L. R., Betz, D. E., \& Sekaquaptewa, D. (2013). The effects of an academic environment intervention on science identification among women in STEM. Social Psychology of Education, 16(3), 377-397. http://doi.org/10.1007/s11218-013-9218-6

Rheinschmidt, M. L., \& Mendoza-Denton, R. (2014). Social Class and Academic Achievement in College: The Interplay of Rejection Sensitivity and Entity Beliefs. Journal of Personality and Social Psychology, 107(1), 101-121. http://doi.org/10.1037/a0036553

Rumberger, R. W. (2010). Education and the reproduction of economic inequality in the United States: An empirical investigation. Economics of Education Review, 29(2), 246-254. http://doi.org/10.1016/j.econedurev.2009.07.006

Schunk, D. H. (1991). Self-efficacy and academic motivation. Educational Psychologist, 26(34), 207-231. http://doi.org/10.1080/00461520.1991.9653133

Smeding, A., Darnon, C., Souchal, C., Toczek-Capelle, M.-C., \& Butera, F. (2013). Reducing the socio-economic status achievement gap at university by promoting mastery-oriented assessment. PLoS One, 8(8), e71678. http://doi.org/10.1371/journal.pone.0071678 
Somers, P., \& Cofer, J. (1997). Singing the Student Loan Blues: Multiple Voices, Multiple Approaches? In Student Loan Debt: Problems and Prospects (pp. 97-128). Washington, D.C.: Institute for Higher Education Policy.

Spencer, B., \& Castano, E. (2007). Social class is dead. Long live social class! Stereotype threat among low socioeconomic status individuals. Social Justice Research, 20(4), 418-432. http://doi.org/10.1007/s11211-007-0047-7

Steele, C. M., Spencer, S. J., \& Aronson, J. (2002). Contending with group image: The psychology of stereotype and social identity threat. Advances in Experimental Social Psychology, 34, 379-440. http://doi.org/10.1016/S0065-2601(02)80009-0

Stephens, N. M., Fryberg, S. A., Markus, H. R., Johnson, C., \& Covarrubias, R. (2012). Unseen disadvantage: How American universities' focus on independence undermines the academic performance of first-generation college students. Journal of Personality and Social Psychology, 102(6), 1178-1197. http://doi.org/10.1037/a0027143

Stephens, N. M., Hamedani, M. G., \& Destin, M. (2014). Closing the Social Class Achievement Gap: A Diversity Education Intervention Improves First-Generation Students’ Academic Performance and All Students' College Transition. Psychological Science, 25(4), 943953. http://doi.org/10.1177/0956797613518349

Stephens, N. M., Markus, H. R., \& Phillips, L. T. (2014). Social Class Culture Cycles: How Three Gateway Contexts Shape Selves and Fuel Inequality. Annual Review of Psychology, 65, 611-634. http://doi.org/10.1146/annurev-psych-010213-115143

Stout, J. G., Dasgupta, N., Hunsinger, M., \& McManus, M. A. (2011). STEMing the tide: using ingroup experts to inoculate women's self-concept in science, technology, engineering, and mathematics (STEM). Journal of Personality and Social Psychology, 100(2), 255270. http://doi.org/10.1037/a0021385 
Symonds, W. C., Schwartz, R. B., \& Ferguson, R. (2011). Pathways to Prosperity: Meeting the Challenge of Preparing Young Americans for the 21st Century. Cambridge, MA: Harvard Graduate School of Education. Retrieved from https://web.archive.org/web/20150909223608/http://dash.harvard.edu/handle/1/4740480

U.S. Census Bureau. (2014). Income, Poverty, and Health Insurance Coverage in the United States: 2013. Washington, D.C.

Verkuyten, M. (2006). Multicultural recognition and ethnic minority rights: A social identity perspective. European Review of Social Psychology, 17(1), 148-184.

http://doi.org/10.1080/10463280600937418

Walton, G. M., \& Cohen, G. L. (2007). A question of belonging: race, social fit, and achievement. Journal of Personality and Social Psychology, 92(1), 82-96. http://doi.org/10.1037/0022-3514.92.1.82

Ziskin, M., Fischer, M. A., Torres, V., Pellicciotti, B., \& Player-Sanders, J. (2014). Working Students' Perceptions of Paying for College: Understanding the Connections between Financial Aid and Work. The Review of Higher Education, 37(4), 429-467. http://doi.org/10.1353/rhe.2014.0028 


\section{Footnotes}

${ }^{1}$ It is important to acknowledge that socioeconomic status (e.g., income) and sociocultural status (e.g., first- versus continuing-generation status) will not always be equivalent-for example, 27 percent of American adults with non-collegiate post-secondary licenses or certificates earn more than the average bachelor's degree holder (Symonds, Schwartz, \& Ferguson, 2011). However, we note that parental education often represents a reasonable proxy for student SES (see Stephens et al., 2012) because across Western developed countries, attaining a university degree is important for finding a high-status, professional job and provides substantial advantages in lifetime earnings (OECD, 2014). Indeed, many of the studies that we reference which examined first-generation university students report that such students were more likely to be low-income compared with their continuing generation counterparts (e.g., Stephens et al., 2012; Stephens et al., 2014).

${ }^{2}$ In keeping with best-practice recommendations (Kraus \& Stephens, 2012), in our three experiments, students' perceived socioeconomic ranking in society was also assessed using the MacArthur scale of subjective social status. However, no significant results emerged when including this measure in place of income in our analyses.

${ }^{3}$ In the interest of examining the education-relevant question of whether the institutional climate influences gaps in academic efficacy and expectations between high- and low-SES students, we also performed the opposite simple slopes analyses. The simple effects of income on both outcome variables were significant and positive in the chilly climate conditionefficacy: $b=.25[.07, .42], t(60)=2.80, p=.007$; expectations: $b=.065[.002, .13], t(59)=2.06$, $p=.044$-and non-significant in the warm climate condition-efficacy: $b=-.018[-.17, .13]$, $t(60)=-.24, p=.81$; expectations: $b=-.024[-.076, .028], t(59)=-.93, p=.36$. Given the significant condition $\times$ income interaction terms (see Table 2), the SES-based gaps in academic 
efficacy and expectations were therefore smaller when the institutional climate was presented as warm versus chilly with regard to socioeconomic diversity.

${ }^{4}$ As in Experiment 1, the simple effect of income on our dependent variable was significant and positive in the chilly climate condition, $b=.04[.01, .07], t(115)=2.72, p=.008$, and non-significant in the warm climate condition, $b=-.0005[-.03, .03], t(115)=-.04, p=.97$. Given the significant condition $\times$ income interaction term (see Table 3), the SES-based gaps in implicit association with high academic achievement were therefore smaller when the institutional climate was presented as warm versus chilly with regard to socioeconomic diversity.

${ }^{5}$ These labels were selected because in the United States (where this study was conducted), the terms "lower-class" and "working-class" are commonly used to refer to individuals on the lower half of the SES divide, while "middle-class" and "upper-class" are both been used to refer to those on the upper end (see Lareau \& Conley, 2008; Stephens et al., 2014).

${ }^{6}$ The effects of this manipulation on SSID and the null effects on belonging and belonging uncertainty among low-SES students have been replicated with an independent pilot sample $(N=49)$.

${ }^{7}$ To avoid perpetuating file-drawer effects, we note that this project included one additional correlational study. In a mass-testing session, 199 undergraduates (89 male, 110 female) from the same private Midwestern American university completed measures of efficacy (as in Experiment 1), SSID (as in Experiment 3), and reported their families household income (as in all three experiments). We found that lower-SES students reported a significantly higher sense of mismatch between their socioeconomic background and the institutional context (i.e., higher SSID scores), $r(160)=-.56$ [-.66, -.45], $p<.001$ (as in Johnson et al., 2011, Study 1), which contributed to a significant indirect effect of SES on academic efficacy, $b=.08[.04, .13]$, $p<.01$ (test of mediation with 5,000 bootstrapped samples; Preacher \& Hayes, 2008). 
Table 1

Demographics of participants.

\begin{tabular}{lccc}
\hline & Experiment 1 & Experiment 2 & Experiment 3 \\
\hline$N$ & 76 & 130 & 131 \\
$M_{\text {age }}(S D)$ & $18.8(.90)$ & $19.2(1.14)$ & $19.8(1.39)$ \\
Gender & & & \\
Male & $43.4 \%$ & $31.5 \%$ & $22.1 \%$ \\
Female & $55.2 \%$ & $68.5 \%$ & $77.9 \%$ \\
Race & & & \\
White & $50.0 \%$ & $53.1 \%$ & $45.8 \%$ \\
Asian & $35.5 \%$ & $27.7 \%$ & $32.4 \%$ \\
Black & $1.3 \%$ & $6.2 \%$ & $7.6 \%$ \\
Latino & $6.6 \%$ & $4.1 \%$ & $3.8 \%$ \\
Middle-eastern & - & $3.1 \%$ & $-7.4 \%$ \\
Multi-racial & $5.3 \%$ & $5.4 \%$ & \\
Class: & & & $24.4 \%$ \\
Freshmen & $75.0 \%$ & $62.3 \%$ & $32.1 \%$ \\
Sophomore & $14.5 \%$ & $22.3 \%$ & $16.8 \%$ \\
Junior & $5.3 \%$ & $10.8 \%$ & $26.7 \%$ \\
Seniors & $5.3 \%$ & $4.6 \%$ & \\
Family household income: & & & $6.9 \%$ \\
\$25,000 or less & $10.5 \%$ & $6.2 \%$ & $4.6 \%$ \\
\$25,001-\$40,000 & $9.2 \%$ & $8.5 \%$ & $12.2 \%$ \\
\$40,001-\$70,000 & $15.8 \%$ & $12.3 \%$ & $13.7 \%$ \\
\$70,001-\$90,000 & $19.7 \%$ & $10.8 \%$ & $23.7 \%$ \\
\$90,001-\$120,000 & $10.5 \%$ & $8.5 \%$ & $9.2 \%$ \\
\$120,001-\$150,000 & $6.6 \%$ & $6.2 \%$ & $8.4 \%$ \\
\$150,001-\$200,000 & $3.9 \%$ & $10.8 \%$ & \\
\$200,001-\$300,000 & $2.6 \%$ & $18.5 \%$ & \\
\$300,001 or more & $5.3 \%$ & $17.7 \%$ & \\
\hline
\end{tabular}

Note. Values do not always total $100 \%$ because some participants did not provide responses to all of the demographic questions. 
Table 2

Statistical results of regressing academic efficacy and expected graduating GPA on income, condition, and their interaction, and the simple effects of condition among low- and high SES students (Experiment 1).

\begin{tabular}{|c|c|c|c|c|c|c|c|c|}
\hline & \multicolumn{4}{|c|}{ Academic efficacy } & \multicolumn{4}{|c|}{ Expected graduating GPA } \\
\hline & $b[95 \%$ CIs $]$ & $t$ & $d f$ & $p$ & $b[95 \%$ CIs] & $t$ & $d f$ & $p$ \\
\hline Main effect of income & $.13[.01, .24]$ & 2.17 & 60 & .034 & $.03[-.02, .07]$ & 1.22 & 59 & .23 \\
\hline Main effect of condition & $.09[-.15, .34]$ & .75 & 60 & .46 & $.009[-.08, .10]$ & .22 & 59 & .83 \\
\hline Condition $\times$ income interaction & $\begin{array}{c}-.13[-.25,-.01] \\
f^{2}=.085\end{array}$ & -2.25 & 60 & .028 & $\begin{array}{c}-.04[-.09,-.003] \\
f^{2}=.078\end{array}$ & -2.15 & 59 & .036 \\
\hline Simple e & $.38[.02, .74]$ & 2.12 & 60 & .038 & $.10[-.02, .23]$ & 1.64 & 59 & .11 \\
\hline Simple effect of condition among high-SES students $(+1 S D)$ & $-.19[-.55, .16]$ & -1.11 & 60 & .27 & $-.09[-.21, .03]$ & -1.46 & 59 & .15 \\
\hline
\end{tabular}

Note. The chilly and warm climate conditions were coded as -1 and 1 , respectively. Degrees of freedom vary slightly across analyses because 1 participant did not report their expected graduating GPA. 
Table 3

Statistical results of regressing students' level of implicit association with high academic achievement income, condition, and their interaction, and the simple effects of condition among low- and high-SES students (Experiment 2).

\begin{tabular}{|c|c|c|c|c|}
\hline & $b[95 \%$ CIs] & $d f$ & $t$ & $p$ \\
\hline Main effect of income & $.02[.001, .04]$ & 2.08 & 115 & .040 \\
\hline Main effect of condition & $.03[-.02, .09]$ & 1.29 & 115 & .20 \\
\hline Condition $\times$ income interaction & $\begin{array}{c}-.02[-.04,-.0003] \\
f^{2}=.035\end{array}$ & -2.01 & 115 & .047 \\
\hline Simple effect of condition among low-SES students $(-1 S D)$ & $.09[.01, .16]$ & 2.31 & 115 & .023 \\
\hline Simple effect of condition among high-SES students $(+1 S D)$ & $-.02[-.09, .05]$ & -.56 & 115 & .58 \\
\hline
\end{tabular}

Note. The chilly and warm climate conditions were coded as -1 and 1 , respectively. 


\section{Table 4}

Correlations between measures in Experiment 3.

\begin{tabular}{|c|c|c|c|c|c|}
\hline & (1) & (2) & (3) & (4) & (5) \\
\hline (1) Income & - & & & & \\
\hline (2) Perceived institutional commitment & $.00[-.17, .17]$ & - & & & \\
\hline (3) Numerical representation & $.06[-.11, .23]$ & $.29 * * *[.12, .44]$ & - & & \\
\hline (4) SSID & $-.61 * * *[-.71, .49]$ & $-.15[-.31, .03]$ & $-.25 * *[-.40,-.08]$ & - & \\
\hline (5) Belonging & $.20 *[.03, .36]$ & $.24 * *[.06, .39]$ & $.18 *[.01, .34]$ & $-.33 * * *[-.48,-.16]$ & - \\
\hline (6) Belonging uncertainty & $.03[-.14, .21]$ & $-.26 * *[-.41, .09]$ & $.05[-.13, .22]$ & $.20 *[.02, .36]$ & $-.35 * * *[-.49,-.18]$ \\
\hline
\end{tabular}

Note. Values in square brackets represent $95 \%$ confidence intervals.

${ }^{\dagger} p<.10 . * p<.05 . * * p<.01 . * * * p<.001$ 
Table 5

Statistical results of regressing perceived institutional commitment to socioeconomic diversity (manipulation check), numerical representation of low-SES students, sensitivity to SES-based identity discrepancy (SSID), belonging uncertainty, and perceived belonging on income, condition, and their interaction, and the simple effects of condition among low- and high-SES students (Experiment 3).

\begin{tabular}{|c|c|c|c|c|c|c|c|c|c|c|c|c|c|c|c|c|c|c|c|c|}
\hline & \multicolumn{4}{|c|}{ Perceived commitment } & \multicolumn{4}{|c|}{ Numerical representation } & \multicolumn{4}{|c|}{$\underline{\text { SSID }}$} & \multicolumn{4}{|c|}{ Belonging uncertainty } & \multicolumn{4}{|c|}{ Belonging } \\
\hline & $b(95 \%$ CIs) & $t$ & $d f$ & $p$ & $b(95 \%$ CIs $)$ & $t$ & $d f$ & $\bar{p}$ & $b(95 \%$ CIs $)$ & $t$ & $d f$ & $p$ & $b(95 \%$ CIs $)$ & $t$ & $d f$ & $p$ & $b(95 \% \overline{C I s})$ & $t$ & $d f$ & $p$ \\
\hline Main effect of income & $.005[-.11, .12]$ & .09 & 126 & .93 & $.35[-.67,1.36]$ & .68 & 126 & .50 & $-.39[-.48,-.30]$ & -8.57 & 122 & $<.001$ & $.03[-.09, .14]$ & .46 & 122 & .65 & $.12[.01, .23]$ & 2.17 & 122 & .032 \\
\hline Main effect of condition & $.25[-.007, .50]$ & 1.93 & 126 & .056 & $1.72[-.56,4.01]$ & 1.50 & 126 & .14 & $-.05[-.25, .15]$ & -.51 & 122 & .61 & $.08[-.18, .34]$ & .64 & 122 & .53 & $.02[-.22, .27]$ & .20 & 122 & .84 \\
\hline Condition $\times$ income interaction & $\begin{array}{c}-.11[-.22, .005] \\
f^{2}=.029\end{array}$ & -1.90 & 126 & .06 & $\begin{array}{c}-1.26[-2.27,-.24] \\
f^{2}=.048\end{array}$ & -2.45 & 126 & .016 & $\begin{array}{c}.09[-.0002, .18] \\
f^{2}=.032\end{array}$ & 1.97 & 122 & .051 & $\begin{array}{c}.02[-.10, .14] \\
f^{2}=.0009\end{array}$ & .33 & 122 & .74 & $\begin{array}{c}-.08[-.19, .03] \\
f^{2}=.018\end{array}$ & -1.48 & 122 & .14 \\
\hline $\begin{array}{l}\text { Simple effect of condition among } \\
\text { low-SES students }(-1 S D)\end{array}$ & $.49[.13, .85]$ & 2.72 & 126 & .008 & $4.57[1.35,7.79]$ & 2.80 & 126 & .006 & $-.26[-.54, .024]$ & -1.81 & 122 & .073 & $.04[-.33, .41]$ & .21 & 122 & .83 & $.21[-.13, .55]$ & 1.23 & 122 & .22 \\
\hline $\begin{array}{l}\text { Simple effect of condition among } \\
\text { high-SES students }(+1 S D)\end{array}$ & $.002[-.36, .36]$ & .01 & 126 & .99 & $-1.12[-4.38,2.14]$ & -0.68 & 126 & .50 & $.14[-.14, .43]$ & 1.00 & 122 & .32 & $.13[-.24, .49]$ & .67 & 122 & .50 & $-.15[-.50, .19]$ & -.87 & 122 & .39 \\
\hline
\end{tabular}

Note. The chilly and warm climate conditions were coded as -1 and 1 , respectively. 

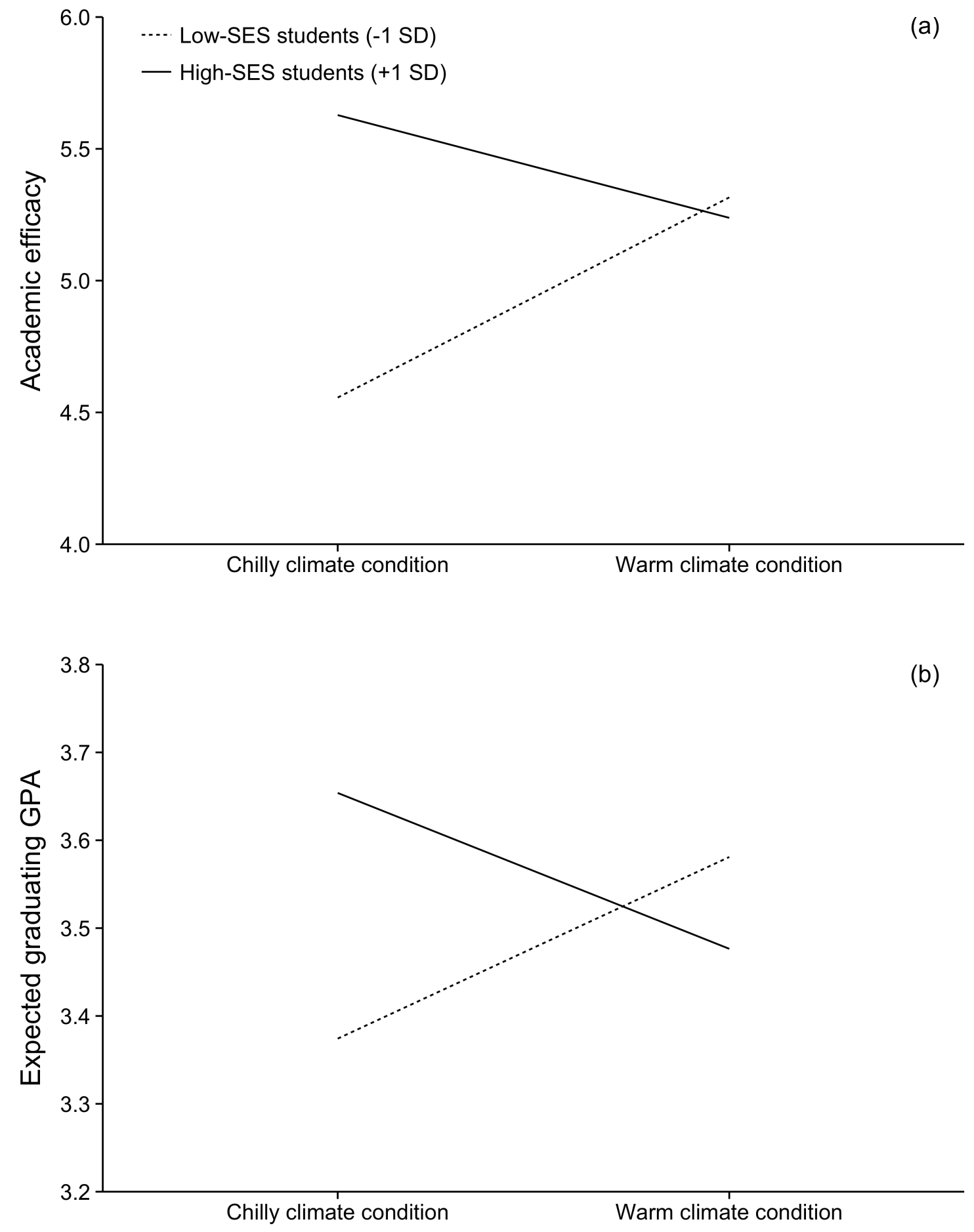

Figure 1. The relationship, by SES, between condition and (a) academic efficacy and (b) expected graduating GPA in Experiment 1. Points are plotted at 1 standard deviation above and below the mean for income. 


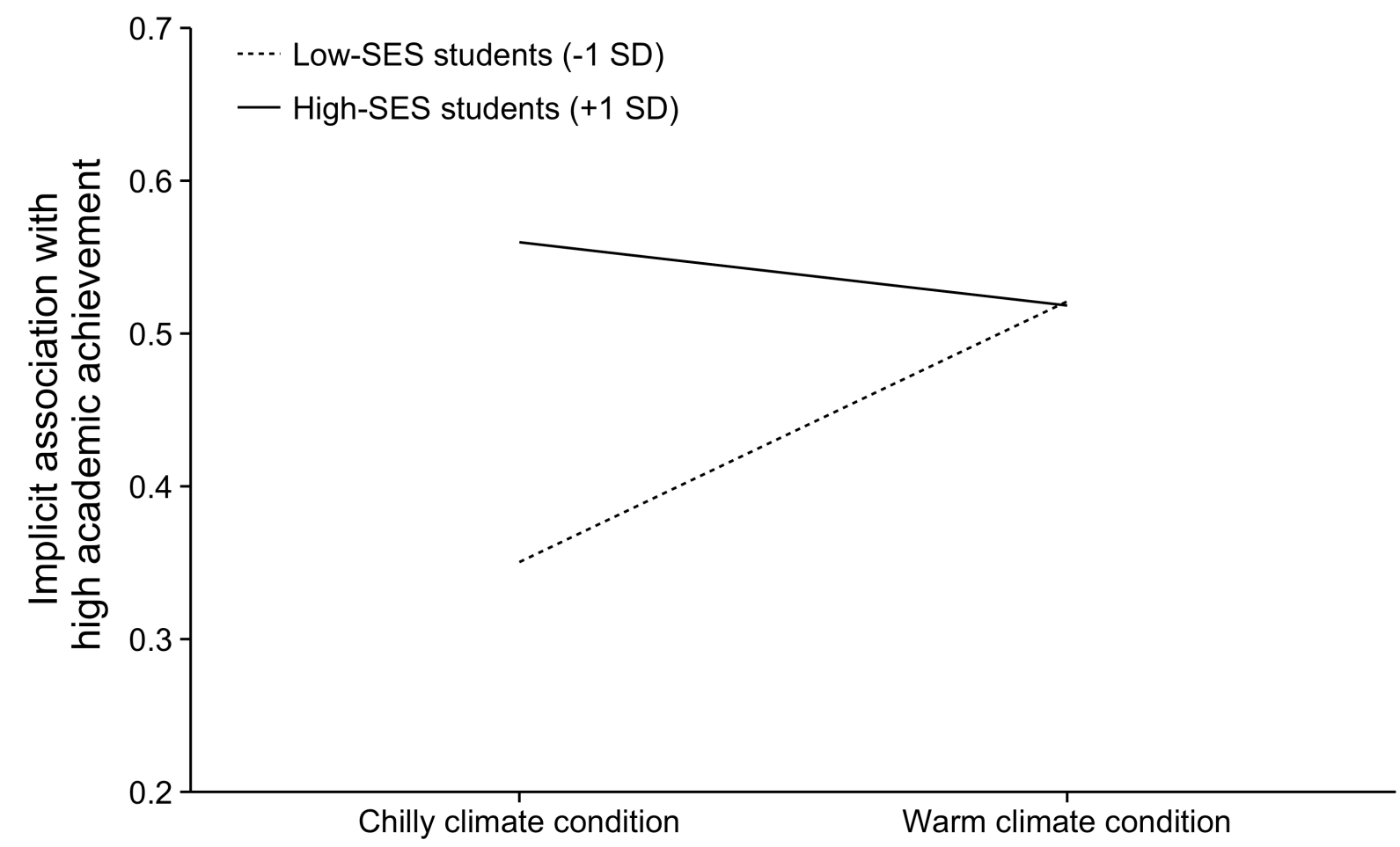

Figure 2. The relationship, by SES, between condition and implicit association with high academic achievement in Experiment 2. Points are plotted at 1 standard deviation above and below the mean for income. 